\title{
Disease alerts and forecasting of zoonotic diseases: an overview
}

\author{
D. P. Kshirsagar ${ }^{1}$, C. V. Savalia ${ }^{1}$, I. H. Kalyani ${ }^{2}$, Rajeev Kumar ${ }^{1}$ and D. N. Nayak ${ }^{1}$ \\ 1. Department of Veterinary Public Health and Epidemiology, Vanbandhu Veterinary College, \\ Navsari Agricultural University, Navsari, Gujarat, India; 2. Department of Microbiology, Vanbandhu Veterinary \\ College, Navsari Agricultural University, Navsari, Gujarat, India \\ Corresponding author: D. P. Kshirsagar, email: drdpk04v@gmail.com \\ Received: 15-08-2013, Revised: 10-09-2013, Accepted: 10-09-2013, Published online: 14-10-2013
}

doi: $10.14202 /$ vetworld.2013.889-896

How to cite this article: Kshirsagar DP, Savalia CV, Kalyani IH, Kumar R and Nayak DN (2013) Disease alerts and forecasting of zoonotic diseases: an overview, Veterinary World 6(11): 889-896.

\begin{abstract}
Epidemiologists are adopting new techniques by the use of Geographical Information System (GIS) to study a variety of animal and zoonotic diseases. Associations between satellite-derived environmental variables such as temperature, humidity, land cover type and vector density is used for disease prediction. Early warning systems rapidly detect the introduction or sudden increase in incidence of any disease of livestock which has the potential to develop into epidemic proportions and/or cause serious socioeconomic consequences or public health concerns. Early warning activities, mainly based on disease surveillance, reporting, and epidemiological analysis, are supported by information systems that enable integration, analysis and sharing of animal health data combined with relevant layers of information such as socioeconomic, production and climatic data. The convergence of factors such as the availability of multi-temporal satellite data and georeferenced epidemiological data, collaboration between scientists, biologists and the availability of sophisticated, statistical GIS creates a fertile research environment. In this paper, we review the Global Early Warning System (GLEWS) that formally brings together human and veterinary public health systems and application of environmental data for study of diseases like avian influenza and Rift valley fever which offers the capability to demonstrate vector-environment relationships and potentially forecast the risk of disease outbreaks or epidemics. An emphasis is also given on components of early warning system and its use for forecasting of animal and zoonotic diseases in India.
\end{abstract}

Key words: FAO, forecasting, global early warning system, geographical information system, OIE, WHO.

\section{I ntroduction}

The ability to detect outbreaks early is important to minimize morbidity and mortality through timely implementation of disease prevention and control measures. The World Trade Center and Anthrax terrorist attacks in 2001 [1] as well as the recent West Nile virus and SARS outbreaks, have motivated many public health authorities to develop early disease outbreak detection systems using non-diagnostic information, often derived from electronic data collected for other purposes [2, 3]. Emerging infectious diseases pose a growing threat to human population. Climatic changes like warmer temperatures and altered rainfall patterns are likely to increase the burden of vector-borne diseases resulting into emergence of zoonotic diseases, too. Many of the world's epidemics are known to be highly sensitive to changes in climate and short-term fluctuations in the weather $[4,5,6]$. "Forecasting" is the monitoring of specific risk parameters helping to predict situations that could lead to the occurrence of a given disease and its subsequent spread. The forecasting of disease helps to predict the course of disease, warn health care workers and adopt control measures to prevent disease outbreaks [7,8].

Passive disease surveillance involves voluntary reporting by people who are ill enough to go to a

Copyright: The authors. This article is an open access article licensed under the terms of the Creative Commons Attribution License (http://creativecommons.org/licenses/by/2.0) which permits unrestricted use, distribution and reproduction in any medium, provided the work is properly cited. treatment center; such centers are therefore only effective for detection and mitigation after a person has been infected. On the other hand, active disease surveillance, which involves "searching" for evidence of disease proactively through routine and continuous monitoring in endemic areas, could help to prevent an outbreak, or slow the rate of transmission at an earlier stage of an epidemic $[9,10]$. The National Oceanic and Atmospheric Administration (NOAA) operate a series of weather satellites that collect operational data for weather forecasting and climate prediction. Besides NASA and NOAA, several European Union countries, Japan, Canada and India have remote sensing satellites that provide global observations to predict occurrence of disease $[11,12,13]$. The use of GIS to map vector species distribution and disease risks has evolved considerably during the past two decades [14]. The objectives of this review are to summarize developments in the application of disease surveillance system for studying animal and zoonotic disease pathogen biology and to identify opportunities for future research on forecasting of diseases.

\section{Objectives of forecasting $[7,8]$}

The objectives employed for forecasting of the diseases include:

1. To study modes of transmission and to understand how to prevent spread of epidemic diseases

2. To monitor the effectiveness of disease control campaigns 

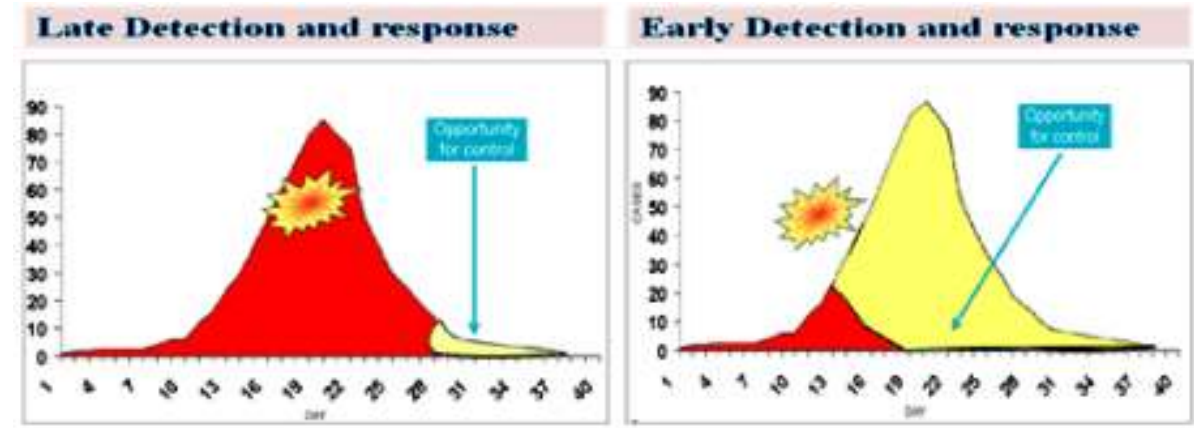

Early warning of outbreaks with a known zoonotic potential prevents human morbidity and mortality

Figure-1. Early and late detection of disease and opportunity to control [15]

3. Emergency preparedness \& disease management strategies

4. To demonstrate knowledge about the epidemiology of diseases

5. To study disease importance from a public health point of view

Advances in disease surveillance systems, epidemiological modelling combined with information technology have generated the expectation that early warning systems are not only feasible but necessary tools to combat the re-emergence and spread of infectious diseases [8].

\section{What is early warning?}

Early Warning is the provision of timely and effective response through the recognized institutions that allows individuals exposed to hazards to take actions to avoid or reduce risk and prepare for an effective response. [15]. Early Warning and Response (EWS) is based on the concept of dealing with a disease epidemic in its early stages. From a public health perspective, early warning of outbreaks with a known zoonotic potential of disease will enable control measures that can reduce human morbidity and mortality rates. The main uses of early warning system include education as an aid to understanding the crucial elements involved in early detection and response to environmental threats $[15,16]$.

\section{Early warning initiatives}

Several initiatives, at national and regional levels have already been developed in the field of early warning. At the international level FAO, OIE and WHO have each developed early warning and Response Systems that systematically collect, verify, analyze and respond to information from a wide variety of sources, including unofficial media reports and informal networks $[17,18]$.

\section{International organizations and their initiative role in development of early warning system}

Office International Des Epizooties (OIE)'S early warning system: OIE was established on $25^{\text {th }}$ January 1924 in Paris. In May 2003 the Office became the World Organization for Animal Health but kept its historical acronym OIE. This organization has set up an animal health information search and verification system for the notification of emerging and reemerging diseases that have not yet been officially notified to the OIE. The framework was designed to empower countries and regional alliances in the fight against Transboundry animal Diseases (TADs). Emergency funds are rapidly mobilized for sending experts from OIE Reference Laboratories to assess the epidemiological situation in a country and define the actions required [19, 20].

World Animal Health Information Database (WAHID) Interface provides access to all data held within OIE's new World Animal Health Information System (WAHIS). It replaces and significantly extends the former web interface named Handistatus II System. A comprehensive range of information is available from immediate notifications and follow-up reports submitted by Country/Territory Members notifying exceptional epidemiological events current in their territory. A six-monthly reporting by member country on the absence or presence and evolution of diseases listed by the OIE and information of epidemiological significance to other countries [21].

Food and Agriculture Organisation: FAO was established on $16^{\text {th }}$ October 1945, Canada then transferred to Rome, Italy. Achieving food security for all is the main goal at the heart of FAO. FAO, through its special EMPRES priority programme established in 1994, developed an early warning and response system [20]. EMPRES Global Animal Disease Information System (EMPRES-i) is a web-based application that has been designed to support veterinary services by facilitating regional and global disease information. Timely and reliable disease information enhances early warning and response to transboundary animal diseases (TADs) including emergent zoonoses, and supports their progressive control and elimination. EMPRES-i aims to clarify disease events worldwide that FAO receives from different sources: country or regional project reports, field mission reports, partner Non-Governmental Organizations (NGOs), cooperating institutions, government Ministries of Agriculture and Health. For verification purposes, EMPRES uses not just official, 
but also unofficial sources of information [22]. A major thrust of the EMPRES activity for early warning and early response has been the development of softwares such as Transboundary Animal Disease Information System (TAD info), Transboundary Animal Diseases Simulator (TAD simulator) and Good Emergency Management Practice (GEMP) [20, 22].

World Health Organisation: WHO was established on $7^{\text {th }}$ April 1948, located at Geneva, Switzerland, concerned with international public health. WHO offers assistance to affected countries in the form of technical advice, supplies and by mounting coordinated international investigations [23]. The Global Outbreak Alert and Response Network (GOARN) is building on new and existing partnerships of national and international institutions and networks, to deal with the global threats of epidemic-prone and emerging diseases in humans and to prepare for rapid deployment and coordination of international resources in response to an outbreak of international importance [23,24]. GOARN aims at ensuring appropriate technical support to affected human populations quickly, assessing risks of rapidly emerging epidemic disease threats and sustaining containment and control of outbreaks by contributing to national outbreak preparedness [24,25]. WHO has developed a comprehensive "Event Management System" to manage critical information about outbreaks and ensure accurate and timely communications between key international public health professionals, including WHO Regional Offices, Country Offices, collaborating centers and partners in the Global Outbreak Alert and Response Network. This system generates a dynamic picture of Alert and Response Operations and provides information for action in a systematic way to enable both WHO and the Global Outbreak Alert and Response Network to prepare better, respond faster, and manage resources more effectively. The WHO event management system is being further strength-ened to support alert and response operational aspects of the revised International Health Regulations [26, 27].

\section{Global early warning and response system (GLEWS)}

GLEWS is a joint system that builds on added value of combining and coordinating the alert, response mechanisms developed by OIE, FAO and WHO [18]. The GLEWS assists in prediction, prevention and control of animal disease threats, including zoonoses through sharing of information, epidemiological analysis and joint field missions to assess and control the outbreak, whenever needed. The GLEWS initiative started with the voluntary participation of representatives of FAO, OIE and WHO, who share the common objective to enhance the early warning and response capacity for the benefit of the international community. Mutual benefit through collaboration has been identified throughout the Early Warning and Response process [28, 29].
Well defined GLEWS are available for highly pathogenic avian influenza (HPAI), Rift Valley fever (RVF) and other vector borne diseases and for rest of the diseases GLEWS is under development [29, 30].

The GLEWS Management Committee (GMC) is responsible for supervising the implementation of the GLEWS agreement, the strategic plan and provides general oversight of GLEWS. The GLEWS Management Committee guides and decides on the different tasks to be accomplished by the GLEWS Task Force which is co-chaired by FAO, OIE and WHO [18]. After being notified a rumor, suspicion or forecast regarding a disease outbreak the information gathered through the respective tracking and verification channels of each organization will be fed into a GLEWS electronic platform information will be further analyzed, monitored and/or sent out as Early Warning Messages. Specific analysis and modeling of trends will be carried out utilizing selected OIE and FAO collaborating centers, OIE and FAO laboratories and WHO collaborating centers. A GLEWS Emergency Response will only be necessary, if there is clear indication for a joint onsite assessment or intervention mission [23, 29].

\section{Aims of GLEWS [18, 23, 28]:}

1. Better international preparedness and rapid containment

2. Improve detection of exceptional epidemiological events at country level

3. Increase timeline and sensitivity of alerts and improve national surveillance and monitoring systems

4. Improve transparency among countries and compliance with reporting to OIE

5. Improve field animal health information quality and provide technical support

6. Strengthening the network between veterinary \& medical laboratories

7. Provide rapid, efficient and coordinated assistance to the affected countries.

GLEWS joint risk analysis for emergent zoonotic diseases: Risk analysis is essential to assess and provide options to mitigate risks associated with the emergence or spread of animal pathogens at the animal/human/ecosystem interface. Risk analysis is one of the core areas that have been recently highlighted for increased collaboration between FAO, OIE and WHO to address emergence of pathogens, in particular on emergent zoonotic pathogens [26].

Joint risk assessment as planned will initially be performed in specific regions for priority zoonotic diseases, such as CCHF, RVF, H5N1 HPAI, Rabies and Brucellosis. In this framework, risk analysis and mapping methodologies will be developed and validated using data available on reported outbreaks, surveillance activities carried out by countries and combining this information with other datasets including land use, trade, livestock population, animal movement, etc. Risk mapping tools are essential to enhance accuracy and sensitivity of early warning activities. Early 
Table-1. GLEWS has given the following list of diseases of common interest [31]

\begin{tabular}{ll}
\hline Zoonotic Diseases & Nonzoonotic Diseases \\
\hline Anthrax & African Swine Fever (ASF) \\
Bovine Spongiform Encephalopathy (BSE) & Classical Swine Fever (CSF) \\
Brucellosis (B. melitensis) & Contagious Bovine Pleuropneumonia (CBPP) \\
Crimean Congo Hemorrhagic Fever & Black quarter \\
Ebola Virus & Haemorrhagic Septicemia \\
Food borne diseases & Foot and Mouth Disease (FMD) \\
Highly Pathogenic Avian Influenza (HPAl) & Peste des Petits Ruminants (PPR) \\
Japanese Encephalitis & \\
Marburg Hemorrhagic Fever & \\
New World Screwworm & \\
Nipah Virus & \\
Old World Screwworm & \\
Q Fever & \\
Rabies & \\
Rift Valley Fever (RVF) & \\
Sheep Pox/Goat Pox & \\
Tularemia & \\
Venezuelan Equine Encephalomyelitis & \\
West Nile Virus &
\end{tabular}

warning messages will be made available to the international community to serve effective response purposes and aid targeting disease surveillance and control activities at the animal-human-ecosystem interface $[26,27,28]$.

\section{GLEWS is supported by the following Regional/ National Networks: [32, 33] \\ 1. FAO (191 Member Nations) \\ 2. WHO (194 Member States) \\ 3. OIE (178 Member Countries) \\ 4. Regional Organizations: EC, SADC, ASEAN, CAN \\ 5. International Reference Laboratories \\ 6. National Authorities \\ 7. Unofficial surveillance programs (PROMED, GPHIN) \\ 8. Laboratory and Epidemiological networks \\ 9. Other partners}

GLEWS approach for Highly Pathogenic Avian Influenza (HPAI): In the aftermath of the avian influenza (AI) crisis triggered by the spread of the highly pathogenic avian influenza H5N1 (HPAI H5N1), the world has been on alert to curb the spread of the disease and to mitigate the risk of a potential human pandemic [10, 34].

The FAO Early Warning System for worldwide monitoring of avian influenza highlights the potential for better integration and exchange of information among key stakeholders, and better understanding of the disease [35]. Through EMPRES I disease tracking list is one example generation of disease information. All confirmed outbreaks, pending and foregoing investigations worldwide in domestic poultry and wild birds are listed. The Disease Tracking List (DTL) also displays the temporal evolution of daily incidence for a $1-y r$ period. This list is shared with national and regional field staff as well as key partner institutions, which are requested to verify and validate the unconfirmed events, and to follow up and search for reliable sources of information. Risk maps are made showing location of confirmed outbreak in poultry and in wild birds. EMPRES I linked with GIS to provide visual representation of disease outbreak and to understand epidemiological factors responsible for TADs emergence and spread $[35,36]$.

These examples show the importance of GIS to identify spatial or spatiotemporal patterns that can be used in developing more rigorous causal hypothesis tests. In conclusion, the ultimate goal of early warning systems is to make information and risk-assessment outcomes available to all relevant stakeholders and to provide the opportunity for timely reaction in the most cost-effective manner [10, 36].

GLEWS approach for Vector borne diseases; Rift Valley Fever (RVF): In parts of East Africa known to be prone to RVF epidemics, remotely-sensed rainfall and vegetation measurements have been integrated into regional and global early warning systems and are used to predict RVF before it reaches epidemic proportions. The ultimate goal of such systems is to safeguard sustained livestock production and have developing countries participate legitimately in local, regional and international trade $[13,35,37]$.

Epidemics of RVF have occurred in southern and eastern Africa at irregular intervals. These epidemics have been associated with above average rainfall after a period of drought and the presence of susceptible exotic breeds of livestock $[13,35]$. Data sets used in these predictions include satellite vegetation index and cold cloud duration (CCD) correlated with climatic changes [37]. Measurements from the Advanced Very High Resolution Radiometer sensor (AVHRR) onboard polar-orbiting satellite series operated by the NOAA are used to generate the normalized difference vegetation index (NDVI) [13, 37].

In East Africa, vegetation index maps have been used together with ground data in monitoring vector populations and RVF viral activity, establishing a correlation between these two parameters. Indeed a detailed analysis was made with virus isolation data over a 25-year period and NDVI records for the study area. As the water table rises to the point where 
flooding may occur, the NDVI ratio approaches 0.43 to 0.45 [38]. The main advantage of using remote sensing for prediction of RVF occurrence in East Africa is the relatively low cost of the system and its use may allow for preventive measures to be taken such as the vaccination of susceptible livestock and mosquito larval control methods [38, 39]. The technology has been used extensively by the FAO to warn countries facing an increased risk of the disease [40, 41].

The components of an Early Warning System (EWS): There are three components of EWS, viz., routine surveillance of the targeted disease, modelling the disease risk based on historical surveillance and contemporary environmental data and forecasting future risk through the use of predictive models with continued epidemiological and environmental surveillance [8].

1. Disease surveillance: A sentinel network is an interactive disease surveillance system that involves the collection of health data on a routine basis, usually by health care professionals over a wide (usually at country level) area [41, 42, 43]. In most industrialized nations, notification of many infectious diseases is a statutory requirement. Rapid collection of data and assessment of regional and national statistics leads to early detection of changes in the incidence of infections [44, 45, 46]. The database also provides information for the planning and implementation of intervention [8, 46]. The growth of such sentinel systems, from independent national networks to coordinate international information systems, has generated a demand for health information systems capable of forecasting disease $[47,48]$.

The present understanding that a facility-based sentinel surveillance system can play an important role in providing information for monitoring communicable diseases, guiding further investigation, evaluating control measures and predicting epidemics [8, 40, 49].

2. Developing a model: Disease forecasting involves modelling, which may be based either on statistical relationships established between past case numbers and environmental predictors 'statistical approach' or an attempt to capture the biology of the transmission processes 'biological approach' [8]. Briefly, the statistical approach requires samples from as wide a range of environmental conditions as possible: predictions arising from this approach assume that the future will be the same as the past, i.e. that the relationships already established between case numbers and environmental variables will persist into the future [50].

The biological approach requires details on all the parameters and variables considered to be important in transmission. Predictions arising from this approach are in theory able to incorporate the effects of environmental changes, or interventions, as long as the impacts of each of these changes on the key transmission parameters are established. It should follow from the above that in the absence of full knowledge of all the transmission pathways for any particular diseases, only the statistical approach is possible. This explains why much of the early epidemiology of poorly-understood diseases such as cancer adopted the statistical route. Statistical models can be extremely powerful, but should be only a temporary substitute for the biological process-based models, whose development exposes our full ignorance of the systems we study. It is only by addressing this ignorance that real progress will be made $[8,50]$.

3: Disease forecasting and prediction: At the heart of early warning is a basic trade-off between the specificity of predictions and the lead times which those predictions can provide. In general, long-range forecasts give the least specific warnings, but have the advantage of providing planners with relatively long lead times. At the other extreme, systems based on early detection of cases provide highly specific information on the timing and location of outbreaks, but allow little time for implementing remedial measures. Any prediction of risk should include an estimate of its reliability $[51,52]$.

Epidemic prevention and control activities usually involve a chain of events and it is important to recognize the potential usefulness of a wide range of indicators, which may be combined to create an integrated prediction strategy. Such a hierarchical system has recently been proposed for tracking malaria epidemics in highland areas of Africa [52].

\section{Geographical information system (GI S)}

GIS is an automated system for the input, storage, analysis and output of spatial information. These data combined with population data and previous disease records for prediction of diseases [53].

Applications of GI S: $[53,54,55]$

1. Forecast epidemics

2. Identify gaps in immunizations

3. Monitor diseases and interventions over time

4. Study Geographical distribution and variation of diseases

5. Map populations at risk and stratify risk factors

6. Monitor Health centers, Routine health workers, equipments \& supplies to service locations

7. Locate nearest Health facility

\section{Forecasting of diseases in I ndia}

In India, the Project Directorate on Animal Disease Monitoring And Surveillance (PD_ADMAS) was established in 1987 by the ICAR to develop a system of disease monitoring and surveillance of economically important livestock diseases, with a goal to design strategic control measures. Although health care infrastructure has grown immensely over the years, disease surveillance system did not get the desired attention as the outbreaks of bird flu (2006), swine flu (2009), and Crimean-Congo hemorrhagic 


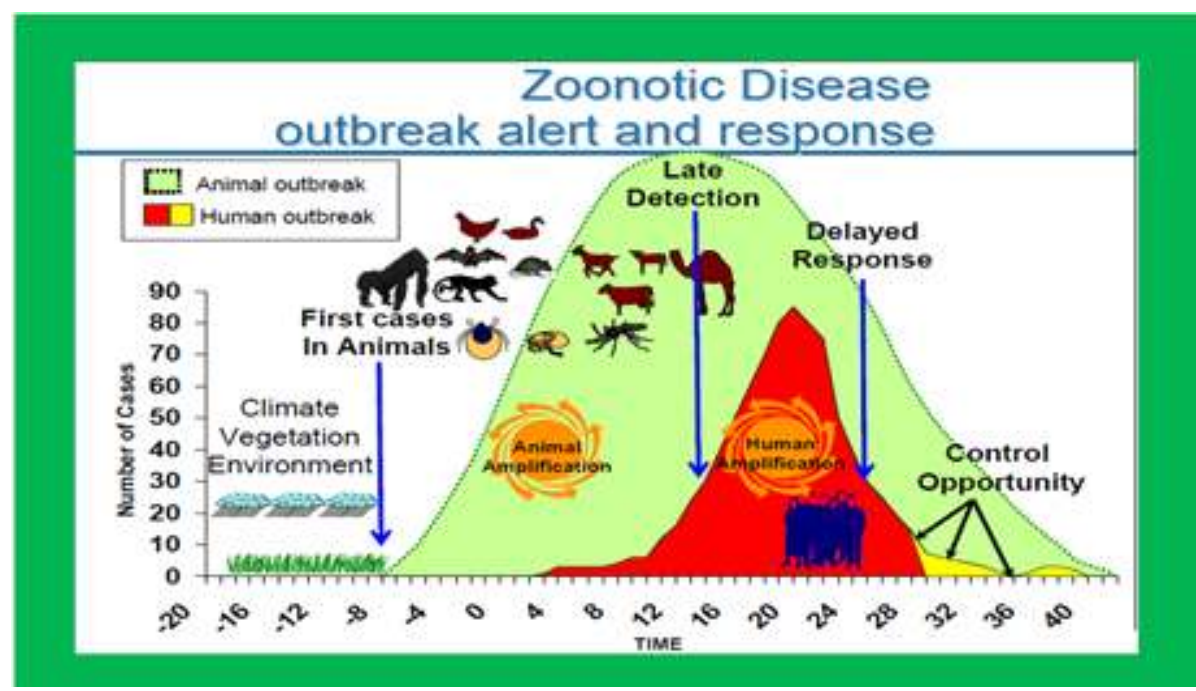

Figure-2. GIS-GLEWS approach for prediction of zoonotic Diseases [23]

fever (2011) in the country highlighted the weaknesses in the current surveillance system [56].

Animal disease surveillance network: At present, animal disease surveillance network in our country include data collection from diseased animal to veterinary doctor at Govt hospital/dispensary through clinical diagnosis- passed to Taluka / Block to District level then to the State Veterinary authorities. The disease information is shared from diagnostic laboratories District, State or Regional level. The State Governments share this information at National level mainly through Department of Animal Husbandry, Dairying and Fisheries (DADF), Ministry of Agriculture, Government of India. [57].

Centre for Animal Disease Research and Diagnosis (CADRAD): It is recognized as Central Disease Diagnostic Laboratory (CDDL) by the Department of Animal Husbandry \& Dairying, Ministry of Agriculture (Govt. of India) since 2001-02 with specific mandate, technical programme and financial support. However, there are five Regional disease diagnosis laboratories located at Kolkata (Eastern), Pune (Western), Jallandhar (Northern), Bangalore (Southern) Guwahati (North-eastern). There are six Quarantine stations viz. Delhi, Mumbai, Chennai, Kolkata, Bangalore and Hyderabad [56, 57].

\section{Disease surveillance and I CAR: [56, 57]}

1. Project Directorate on Foot and Mouth Disease (PDFMD)

2. Project Directorate on Animal Disease Monitoring and Surveillance (PD_ADMAS)

3. High Security Animal Disease laboratory (HSADL, IVRI)

PDADMAS (Project Directorate on Animal Disease Monitoring and Surveillance) Bangalore: This is the agency working on surveillance of major economically important animal diseases including zoonoses. Advances in information technology provide adequate computing techniques to develop a National livestock disease information system which is the prime need of today.
1. "Epi- Info" (Analysis Project On Livestock Disease Forecasting/Forewarning)"

2. "NADRES(National Animal Disease Referral Expert System)"

Epi- I nfo ${ }^{\mathrm{TM}}$ (Analysis Project on Livestock Disease Forecasting/ Forewarning): PD_ADMAS has developed an innovative india. admas-Epitrak epidemiology software which is a dynamic and interactive livestock disease related database supported by GIS. This software addresses the needs of data collection, retrieval, analysis and critical reporting of disease events as and when they occur and is useful to students and vet colleges, field veterinarians, administrators and technocrats [57].

NADRES (National Animal Disease Referral Expert System): This is a component of National Agricultural Technology Program funded mission mode sub project on weather based animal disease forecasting and animal health information system through disease monitoring and surveillance [58].

\section{Conclusions}

Early detection and response provides better preparedness for effective control and containment of disease outbreaks. Animal Disease Surveillance is a key for improving disease analysis, early warning and prevents the spread of diseases. GLEWS strengthen early warning systems of OIE/ FAO/ WHO for the benefit of international community by using recent advances in communication $\&$ information technologies. GIS offers lot of scope in Veterinary Public Health research especially for surveillance, mapping and ecological analysis of emerging zoonoses. The well defined GLEWS are available for HPAI, RVF and some vector borne diseases, while for the rest diseases GLEWS is under development. PD_ADMAS and other surveillance and information networks are stand alone in India and there is a need for complete review of surveillance system for animal diseases which may guide important policy decisions. Successful implementation of EWS 
is dependent on efficacy of national disease surveillance program, degree of awareness among field veterinarians, technicians, extension specialists, and farmers about clinical and epidemiological features of diseases.

\section{References}

1. Ackelsberg, J., Balter, S., Bornschelgel, K., Carubis, E., Cherry, B. (2002) Syndromic surveillance for bioterrorism following the attacks on the World Trade Center-New York City, 2001. (MMWR) Morbidity Mortality Weekly Report 51: 13-15.

2. Kulldorff, M., Heffernan, R., Hartman, J., Assunc, R., Mostashari, F. (2005) A Space-Time Permutation Scan Statistic for Disease Outbreak Detection PLoS Medicine 2(3):216-224.

3. Epstein, P.R. (2002) Climate Change and Infectious Disease: Stormy Weather Ahead Epidemiology 13(4):373375.

4. Mills, J.N., Kenneth, L., Gage, Khan, A. (2010) Potential Influence of Climate Change on Vector-Borne and Zoonotic Diseases: A Review and Proposed Research Plan, Environmental Health Perspectives 118(11):1507-1513.

5. Gale, P.T., Drew, L., Phipps, P., David, G., Wooldridge, M. (2009) The effect of climate change on the occurrence and prevalence of livestock diseases in Great Britain: a review Journal of Applied Microbiology 106-1409-1423.

6. Thornton. P.K., Van de Steeg, J., Notenbaert, A., Herrero, M. (2009) The impacts of climate change on livestock and livestock systems in developing countries: A review of what we know and what we need to know, Agricultural Systems 101: 113-127.

7. Hay, S.I., Tucker, C.J., Rogers, D.J. and Packer, M.J. (1996) Remotely sensed surrogates of meteorological data for the study of the distribution and abundance of arthropod vectors of disease. Annals of Tropical Medicine and Parasitology. 90:1-19.

8. Myers, M.F., Rogers, D.J., Cox, J., Flahault, A., Hay, S.I. (2000) Forecasting Disease Risk for Increased Epidemic Preparedness in Public Health. Advances in Parasitology. 47: 309-330.

9. Ogden, N.H., Bouchard, C., Kurtenbach, K., Margos, G., Lindsay, L.R., Trudel, L. (2010) Active and passive surveillance and phylogenetic analysis of Borrelia burgdorferi elucidate the process of Lyme disease risk emergence in Canada. Environ Health Perspect 118:909-914.

10. Martin, V., Dobschuetz, S., Lemenach, A., Rass, N. Schoustra, W., DeSimone, L. (2007) Early warning, database, and information systems for avian influenza surveillance. Journal of Wildlife Diseases, 43(3): S71-S76.

11. Kalluri, S., Gilruth, P., Rogers, D., Szczur, M. (2007) Surveillance of Arthropod Vector-Borne Infectious Diseases Using Remote Sensing Techniques: A Review PLoS Pathogens 3(10): 1361-1371.

12. Hargrove, W.W., Spruce, J.P., Gasser, G.E., Hoffman, F.M. (2009) Toward a national early warning system for forest disturbances using remotely sensed canopy phenolog. Photogrammetric Engineering \& Remote Sensing 75:11501156.

13. Martin, V., Simone, L., Lubroth, J., Ceccato, P., Chevalier, V. (2007) Perspectives on using remotely-sensed imagery in predictive veterinary epidemiology and global early warning systems. Geospatial Health 2(1): 3-14.

14. Beck, L.R., Lobitz, B.M., Wood, B.L. (2000) Remote sensing and human health: New sensors and new opportunities. Emerging Infectious Diseases 6: 217-226.

15. Grasso, V. and Singh, A. (2011) Early Warning Systems: State-of-Art Analysis and Future Directions. Draft report United Nations Environment Programme (UNEP) 1-10.

16. Farnswortha, M.L., Westb, C.H., Fitchett, S., Newmanb,
S.H., Rocqueb, S., Simoneb, L.D., Lubrothb, J. and Pintob, J. (2010) Comparing national and global data collection systems for reporting, outbreaks of H5N1 HPAI Preventive Veterinary Medicine 95:175-185.

17. WHO (World Health Organization) (2006) Global Early Warning and Response System for Major Animal Diseases, including Zoonoses (GLEWS). Final version adopted by the three organizations tripartite 2006:1-26.

18. WHO (World Health Organization) (2010) Global Early Warning System for Major Animal Diseases, Including Zoonoses (GLEWS). At http://www.who.int/zoonoses/ outbreaks/glews/Accessed on 15th July 2013.

19. OIE (World Organization for Animal Health) (2008) Climate change: the impact on the epidemiology and control of animal diseases Scientific and Technical Review 27(2): 467-84.

20. Food and Agriculture Organization (FAO) (2011) Challenges of animal health information systems and surveillance for animal diseases and zoonoses. Proceedings of the international workshop organized by FAO, 23-26 November 2010, Rome, Italy.

21. OIE (World Organization for Animal Health) (2013) World Animal Health Information System (WAHIS) Available on http://www.oie.int/wahis2/public/index.php/. Accessed on 3rd September 2013.

22. FAO (2002) Towards a global early warning system for animal diseases. EMPRES (Transboundary animal disease bulletin) 20:1.

23. Formenty, P. (2009) When animal disease strikes to human an integrated approach in time and space. Epidemic and Pandemic alert \& Response, International meeting on emerging diseases 2009, Vienna, Austria.

24. Ridder, B.A. and Formenty, P. (2011) From Forecasting to Control of Zoonotic Diseases: Linking Animal and Human Systems. Available at http:outbreak@who.int/outbreak network Accessed on 1st June 2012.

25. Jebara, K.B. (2004) Surveillance, detection and response: managing emerging diseases at national and international levels. Rev. sci. tech. Off. int. Epiz. 23 (2):709-715.

26. WHO (World Health Organization) (2013) Zoonoses and Veterinary public health Available at http:// www. who. int/ zoonoses/outbreaks/glews/en/ Accessed on 10th May, 2013.

27. FAO (Food and Agricultural organization) (2011) Fourth Global Steering Committee Meeting of the Global Framework for the Progressive control of Transboundary animal diseases (GF-TADS GSC4) 18-19 Oct 2011 FAO Headquarters Rome (Italy).

28. FAO-OIE-WHO (2010) The FAO-OIE-WHO Collaboration Sharing responsibilities and coordinating global activities to address health risks at the animal-human-ecosystems interfaces A Tripartite Concept Note. http://www.glews.net/ wpcontent/uploads/2011/04/html Accessed on 15th July 2013.

29. WHO (World Health Organization) (2013) Outbreak surveillance and response in humanitarian emergencies: WHO guidelines for EWARN implementation. Geneva, Switzerland: Available http://www.who.int/disease control _emergencies/publications html Accessed 30th March, 2013.

30. Ahmed, J., Bouloy, M. Ergonul, O, Fooks, A.R., Paweska, J., Chevalier, V., Drosten,V., Moormann, R., Tordo, N Vatansever, Z., Calistri, P., Estrada-Pria, A., Mirazimi, A., Unger, H., Yin, H., Seitzer, U. (2009) International network for capacity building for the control of emerging viral vector borne zoonotic diseases: Arbo-zoonet Eurosurveillance 14 (12):1-4.

31. Global Early warning system for major animal diseases including zoonoses (2013) GLEWS disease priority list Available at http: http://www.glews.net Accessed on 10th May 2013.

32. Pinto, J. (2012) The Global Early Warning System for Major Animal Diseases including Zoonoses. One Health-One Planet-One Future-Risk and Opportunities. Davos, Switzerland Global Risk Forum Summit 2012, 
33. FAO (Food and Agricultural organization) (2012) Fourth GF-TADS for Europe Steering Committee Meeting (SC4). 26-27 Jan 2012 Brussels (Belgium).

34. Angot, J.L., (2009) The governance of veterinary services and their role in the control of avian influenza. Rev. Sci. Tech. Off. Int. Epiz. 28: 397-400.

35. Martin, V., Sims, J., Lubroth, D., Pfeiffer, J., Slingenber, H, and Domenech, J. (2006) Epidemiology and ecology of highly pathogenic avian influenza with particular emphasis on South East Asia. Developments in Biologicals 124: 23-36.

36. Gilbert, M.X., Xiao, P., Chaitaweesub, W., Kalpravidh, S., Premashthira, S., Boles and Slingenbergh, J. (2007) Avian influenza, domestic ducks and rice agriculture in Thailand. Agriculture, Ecosystems \& Environment 119:409-415.

37. Davies, G. and Martin, V. (2003) Recognizing Rift Valley fever. FAOAnimal Health Manual 17.

38. Linthicum, K.J., Bailey, C.L., Davies, F.G. and Tucker, C.J., (1987) Detection of Rift Valley fever viral activity in Kenya by satellite remote sensing imagery. Science 235: 1656-1659.

39. Linthicum, K.J., Anyamba, A., Tucker, C.J., Kelley, P.W., Myers, M.F., Peters, C.J. (1999) Climate and satellite indicators to forecast Rift Valley fever epidemics in Kenya. Science 285: 397-400.

40. Paweska, J., Blumberg, L., Weyer, J., Kemp, A., Leman, P., Archer, B. (2008) Rift Valley fever outbreak in South Africa, NICD-NHLS Communicable Diseases Surveillance Bulletin, 6(2):1-2.

41. CDC (Centers for Disease Control and Prevention). (2010) Climate Change and Public Health. Available: http:// www. cdc.gov/nceh/climatechange/ Accessed on 16 June 2013.

42. Girard, J.F. (1997) Sentinel networks: the National Public Health Network. Bulletin of the Academy of National Medicine. 179:919-925.

43. CDC (Centers for Disease Control and Prevention) (2010) Early Warning Disease Surveillance after a Flood EmergencyPakistan. Morbidity and Mortality Weekly Report 61 (49): 1002-1007.

44. Lafferty, K.D. (2009) The ecology of climate change and infectious diseases. Ecology 90:888-900.

45. Heymann, D.L. and Rodier, G.R. (1998) Global surveillance of communicable diseases. Emerging Infectious Diseases. 4:362-365.

46. Childs, J.E. and Gordon, E.R. (2009) Surveillance and
Control of Zoonotic Agents Prior to Disease Detection in Humans. Mount Sinai Journal of Medicine, 76: 421-428.

47. Flahault, A., Dias-Ferrao, V., Chaberty, P., Esteves, K., Valleron, A.J., Lavanchy, D. (1998) Flunet as a tool for global monitoring of influenza on the web. Journal of the American Medical Association. 280:1330-1332.

48. Nabarro, D.N. and Tayler, E.M. (1998) The roll back malaria campaign. Science. 280:2067-2068.

49. Shalala, D.E. (1998) Collaboration in the fight against infectious diseases. Emerging Infectious Diseases. 4:15-18.

50. Frisen, M. (1992) Evaluation of methods for statistical surveillance. Statistics in Medicine. 11:1489-1502.

51. Livestock and Dairy Development Department (2012) Animal Disease Management -Assessment and Way Forward Punjab Government Efficiency Improvement Programme Crown agents: 7-9.

52. Cox, J.S., Craig, M.H., Le, Sueur, D., Sharp, B. (1999) Mapping Malaria Risk in the Highlands of Africa. MARA/HIMAL Technical Report; Durban.

53. Connor, S.J., Thomson, M.C., Flasse, S.P., Williams, J.B. (1995) The use of low-cost remote sensing and GIS for identifying and monitoring the environmental factors associated with vector borne disease transmission. GIS for Health and the Environment: 75-87.

54. Khan, O.A. (1999) The First International Health Geographics Conference. American Journal of Public Health, 1(2): 55-65.

55. Boone, J.D., Kenneth, C., McGwire, Otteson, E.W., Robert, S., DeBaca, Kuhn, E.A., Villard, P., Brussard, P.F. and Jeor, S.C. (2000) Remote Sensing and Geographic Information Systems: Charting Sin Nombre Virus Infections in Deer Mice, Emerging Infectious Diseases 6(3):248-258.

56. Project Directorate on Animal Disease Monitoring and Surveillance PD_ADMS. (2011) PDADMAS News January-June 2011 1(1): Available on http: www.pdadmas. ernet. Accessed on 18th July 2013.

57. Hemadri, D. and Kumar, G.B. (2013) Vision 2050. Project Directorate on Animal Disease Monitoring \& Surveillance, Hebbal, Bengaluru available at http: www.pdadmas.ernet.in Accessed on 18th July 2013.

58. National Animal Disease Referral Expert System NADRES (2011) PDADMAS News January-June 2011. 1(1): Available at http: http://www.nadres.res.in Accessed on 18th July 2013. 